1. Komabayashi T, Raghuraman K, Raghuraman R et al. Dental education in India and Japan: implications for U.S. dental programs for foreign-trained dentists. J Dent Educ 2005; 69: 461-469.

2. Faizuddin M. Moving ahead...Setting new standards. J Indian Soc Periodontol 2012; 16: 2. Available online at http://www.jisponline.com/text. asp?2012/16/1/2/94593 (accessed June 2015).

3. Garmel G M. Mentoring medical students in academic emergency medicine. Acad Emerg Med 2004; 11: 1351-1357.

DOI: 10.1038/sj.bdj.2015.541

\section{ORAL HEALTH AND NUTRITION}

\section{Aspartame and other materials}

Sir, it is with interest that I read that Pepsi have now stopped using aspartame in their diet drinks in America, reportedly as a response to the public's health concerns over its use in diet drinks. There is increasing public concern regarding the use of artificial sweeteners, and more widely in general chemicals in our foods, that may be influencing our health.

In the late 1990s we had a tooth friendly endorsement of aspartame-containing products as part of a BDA campaign. I wrote a letter concerned about the general health effects that this may cause and got rather lambasted by the profession in the letters' section for such an approach.

However, the BDA subsequently stopped endorsing sugar free products, certainly those containing aspartame, stating that it was looking at different opportunities. Maybe it was foresight over this controversy. I think it is right not to promote the use of such a potentially health-harming product.

In a modern and up-to-date society, we have to look at other chemicals that are still accepted, endorsed by the BDA and considered safe by our regulatory bodies. Is it not now the time to look at other materials used in dentistry? The biggest and possibly the most controversial dental product being mercury and its use with dental amalgams and closely followed by fluoride. We should look at the role of amalgam fillings from the patient's health perspective (and the dental team's) rather than ease of use, convenience and cost.

If we are the profession I hope we are, we should look at the present scientific and possibly the anecdotal information available and make the decision ourselves rather than let someone else make the decisions for us. Ultimately, we were the ones endorsing aspartame-containing drinks and are the ones placing fillings containing mercury in people's mouths as well as prescribing fluoride. At the BDA Conference there was an informative presentation on the comparison of amalgams and composites.
Let's embrace the narrowing of the gap between these materials and work towards stopping using amalgam just in case it is as harmful as the aspartame we now avoid. Have we done a current upto-date review of the literature to defend our position if at a later date these substances are found to be harmful? I look to open a debate and scientifc discussion on this matter.

J. Roberts Huddersfield DOI: 10.1038/sj.bdj.2015.542

\section{STEREOPSIS IN DENTISTRY}

\section{Dismal sporting skills}

Sir, I read with interest the literature review published in this Journal ${ }^{1}$ about the importance of 3-D vision in dentistry, and the benefits of two good eyes as our profession develops ever more detailed operative techniques. The authors suggest that stereoacuity should be tested and regularly monitored in all dental students. This would put me at the bottom of the class as I have lived with a 'lazy' left eye throughout my career; it is no use at all in dentistry, reading, or anything much else for that matter.

I cannot say this lazy eye has held me back and have never felt disadvantaged in adopting to new techniques. I am now in my fourth decade of dental practice and I like to think I have made a reasonable success of my career, so anyone with similar issues reading the article should take some comfort from this.

My sporting skills, however, especially those involving a moving ball, have always been dismal, and my confident swipes at high velocity tennis, cricket and squash balls give opponents great hope, as the ball sails sweetly past my racquet/bat with monotonous regularity.

Can I suggest golf to those similarly affected, as the ball remains stationary before it is hit?

S. Duffy
Harrogate
DOI: $10.1038 /$ sj.bdj.2015.543

1. Syrimi M, Ali N. The role of stereopsis (three-dimensional vision) in dentistry: review of the current literature. Br Dent J 2015; 218: 597-598.

\section{ENDODONTICS}

\section{To intervene or not to intervene}

Sir, Your recent paper ${ }^{1}$ allows me to hope that the age-old dilemma for the dental profession - whether or not to intervene when asymptomatic apical periodontitis is diagnosed - might soon be resolved.

A 2014 paper in the $B D J^{2}$ provides us with a rough estimate of the number of adult patients in the UK who may have asymptomatic apical periodontitis; it was detected in 49\% of the 136 patients and confirmed that high quality root canal treatment is crucial to ensure a favourable treatment outcome.

The issue of standards in endodontic treatment is topical. Martin Kelleher has broached the issue in an opinion piece ${ }^{3}$ in which he refers to a dramatic fall since 2006 in the number of dentists doing root fillings combined with an increase in the number of extractions. Clearly, these figures should be reversed. A first step for the General Dental Council - whose slogan is: protecting patients, regulating the dental team - might be to ensure that all dental students complete a uniform quota of endodontic cases to a high standard prior to graduating. If standards can be improved, apical periodontitis will be less of an issue.

But there still needs to be clear guidelines for the benefit of both patients and the profession. I would like to think that as a result of your opinion paper and accompanying model for a study, these are within our grasp.

\section{J. Webber} London

1. van der Waal S V, Lappin D F, Crielaard W. Does apical periodontitis have systemic consequences? The need for well-planned and carefully conducted studies. Br Dent J 2015; 218: 513-516.

2. Carrotte P. Apical periodontitis and the technical quality of root canal treatment in an adult sub-population in London. Br Dent $J$ 2014; 216: 586-587.

3. Kelleher M. Regulations and regulators: Who will guard the guards? Dent Update 2015; 42: 406-410.

DOI: 10.1038/sj.bdj.2015.544 